Letter to the Editor

\title{
Flawed methods explain the effect of mammography screening in Nijmegen
}

\author{
KJ Jørgensen ${ }^{*}, 1$ \\ 'The Nordic Cochrane Centre, Rigshospitalet, Department 3343, Blegdamsvej 9, Copenhagen DK-2 I00, Denmark
}

British Journal of Cancer (201 I) I 05, 592-593. doi:I0.1038/bjc.2011.264 www.bjcancer.com

Published online 26 July 2011

(c) 201I Cancer Research UK

Sir,

van Schoor et al (2011) apply a case-control design to evaluate the Nijmegen breast screening programme, which began in 1975. They estimate a $65 \%$ reduction in breast cancer mortality during the period 1992-2008 by calculating the odds ratio for the breast cancer death rate for screening participants $v s$ non-participants. It is not the first time that this study design has been used to claim a large effect of screening mammography in Nijmegen (Verbeek et al, 1984). In 1984, some of the same authors used a similar design to claim a 52\% reduction in breast cancer mortality by 1981 . This large effect was surprising, as the same authors reported that there was no actual reduction in the breast cancer mortality rate in Nijmegen at that time, when participants and non-participants were combined (Verbeek et al, 1984). Interestingly, although the new study covered a longer observation period (1975-1991), it identified an effect of only $28 \%$ in Nijmegen by 1991 (van Schoor et al, 2011). No explanation for this discrepancy was provided, although the title of their new study emphasises the increasingly strong reduction in breast cancer mortality due to screening over time' (van Schoor et al, 2011).

The case-control design has been shown to provide severely flawed results when estimating the effect of mammography screening programmes, with specific reference to the 1984 study of Nijmegen (Janzon and Andersson, 1991). The investigators of the Malmö randomised screening trial elegantly demonstrated how large the bias can be. They compared breast cancer mortality rates in participants $v s$ non-participants within the screening arm of their trial (Janzon and Andersson, 1991). After 9 years, by the end of 1986 , the relative risk for breast cancer mortality was 0.96 (95\% CI $0.68-1.35$; Table 1) when the trial was analysed as a randomised trial (Janzon and Andersson, 1991). But when the authors used the case-control design of Verbeek et al (1984) and van Schoor et al (2011), they found a significant (but false) 58\% 'effect' (OR matching for age; $0.42,95 \%$ CI $0.22-0.78$; Table 2; Janzon and Andersson, 1991).

This impressive but spurious 'effect' in the Malmö trial was attributed to selection bias (Janzon and Andersson, 1991). Some women decide not to go for screening because they fear something may be wrong, and women from lower socioeconomic groups also often choose not to be screened, but have higher mortality from a range of diseases, including breast cancer. The Malmö trial authors

*Correspondence: Dr KJ Jørgensen; E-mail: kj@cochrane.dk

Published online 26 July 2011 concluded that we must therefore compensate for selection bias if we apply the case-control design to evaluations of public health effects of mammography screening. They also demonstrated that the arguments against the importance of selection bias previously presented by Verbeek et al (1984) were flawed (Janzon and Andersson, 1991). Verbeek et al (1984) compared incidence rates in Nijmegen with those in the unscreened area of Arnhem close by to argue that selection bias was unimportant. The obvious comparison would have been the breast cancer mortality rates in these two areas, but this was not done and would likely have provided unfavourable results, as breast cancer mortality rates in Nijmegen were not actually reduced. As the Malmö trial found no effect by 1986 (an effect only appeared later), whereas the 'effect' was $58 \%$ when the case control design was used, the $65 \%$ 'effect' found by van Schoor et al (2011) is unimpressive.

Many of these concerns were also raised in the 2002 WHO/IARC report (Vainio and Bianchini, 2002) in its evaluation of casecontrol studies of mammography screening, including again

Table I The Malmö mammographic screening trial assessed as a randomised trial (Janzon and Andersson, 1991)

\begin{tabular}{lcc}
\hline & Invited $(\boldsymbol{n}=\mathbf{2 1 ~ 0 8 8})$ & Controls $(\boldsymbol{n}=\mathbf{2 1} \mathbf{1 ~ 1 9 5})$ \\
\hline Proportion & $50 \%$ & $50 \%$ \\
Breast cancer deaths & 63 (3I were non- & 66 \\
Mortality rate & participants) & $0.311 \%$ \\
Relative risk & $0.299 \%$ & $0.96(95 \% \mathrm{Cl} 0.68-1.35)$ \\
\hline
\end{tabular}

Table 2 The Malmö trial assessed using a case-control design Janzon and Andersson, |991)

\begin{tabular}{lccr}
\hline & $\begin{array}{c}\text { Living } \\
\text { controls } \\
\text { (random sample) }\end{array}$ & $\begin{array}{c}\text { Women dead } \\
\text { from } \\
\text { breast cancer }\end{array}$ & Total \\
\hline Participation in screening & & & \\
$\quad$ Yes & 229 & 36 & 265 \\
$\quad$ No & 71 & 24 & 95 \\
$\begin{array}{l}\text { Total } \\
\text { Crude odds ratio }\end{array}$ & 300 & 360 & \\
$\begin{array}{l}\text { Adjusted (matching for age) } \\
\text { odds ratio }\end{array}$ & \multicolumn{4}{c}{$0.42(95 \% \mathrm{Cl} 0.22-0.78)$} \\
\hline
\end{tabular}


specifically the study by Verbeek et al (1984), which led them to conclude that, 'observational studies based on individual screening history, no matter how well designed and conducted, should not be regarded as providing evidence of an effect of screening' (Vainio and Bianchini, 2002).

Recent studies with much stronger designs that compare screened with non-screened areas within the same countries over the same time period have not found an effect of current mammography screening programmes (Jørgensen et al, 2010;

\section{REFERENCES}

Janzon L, Andersson I (1991) The Malmö mammographic screening trial. In Cancer Screening, Miller AB, Chamberlain J, Day NE et al (eds). pp 37 - 44. Cambridge University Press: Cambridge

Jørgensen KJ, Zahl PH, Gøtzsche PC (2010) Breast cancer mortality in organised mammography screening in Denmark. A comparative study. BMJ 340: $\mathrm{c} 1241$

Kalager M, Zelen M, Langmark F, Adami HO (2010) Effect of screening mammography on breast-cancer mortality in Norway. $N$ Engl J Med 363: $1203-1210$
Kalager et al, 2010). The Norwegian study (Kalager et al, 2010) was criticised because the average follow-up of 2.2 years was considered too short, but this is a misunderstanding. This was the follow-up after diagnosis. The follow-up from start of screening was 6.6 years, which is when an effect was seen in the randomised trials.

\section{Conflict of interest}

The author declares no conflict of interest.

Vainio H, Bianchini F (eds). (2002) IARC Handbooks of Cancer Prevention, Vol. 7, Breast Cancer Screening. IARC Press: Lyon

van Schoor G, Moss SM, Otten JDM, Donders R, Paap E, den Heeten GJ, Holland R, Broeders MJM, Verbeek ALM (2011) Increasingly strong reduction in breast cancer mortality due to screening. Br J Cancer 104: 910-914

Verbeek AL, Hendriks JH, Holland R, Mravunac M, Sturman F, Day NE (1984) Reduction of breast cancer mortality through mass screening with modern mammography. First results of the Nijmigen project, 1975-1981. Lancet 1: 1222-1224 